\title{
REAVI
}

\section{SISTEMA DE CONTROLE INTERNO NA GESTÃO PÚBLICA DE UM MUNICÍPIO DE PEQUENO PORTE}

\author{
Paulo Fernando Marschner ${ }^{1}$, Analisa Tiburski Sommer ${ }^{2}$, Larissa Marx Welter ${ }^{3}$ \\ ${ }^{1}$ Universidade Federal de Santa Maria \\ ${ }^{2}$ Universidade Estadual do Rio Grande do Sul \\ ${ }^{3}$ Universidade Federal do Rio Grande do Sul \\ ${ }^{1}$ paulofernandomarschnerehotmail.com \\ 2 analisa-somer@uergs.edu.br \\ 3 larissamarxwelte@gmail.com
}

\section{Resumo}

O objetivo deste trabalho é analisar o controle interno na gestão pública de um município de pequeno porte a partir de três perspectivas: (i) perfil do controller, (ii) situação do controle interno, e (iii) planejamento e execução das atividades, e verificar, se o conjunto destes estão aderentes ao regimento legal e se aproximam-se da realidade de outros municípios já estudados. O potencial problema do controle interno na gestão pública de municípios de pequeno porte, destacado por Castro (2013) é que nestas prefeituras, existe a tendência da centralização de tarefas em uma mesma pessoa, o que é corroborado por trabalhos anteriores. Entretanto poucos destes trabalhos analisam a dinâmica do controle interno em municípios de pequeno porte. Em termos metodológicos, a pesquisa teve natureza qualitativa, abordagem descritiva. Para coleta de dados, por sua vez, aplicou-se um questionário ao responsável pelo controle interno da prefeitura estudada, com 19 questões, elaborado a partir do trabalho de Roza, Lunkes e Alberton (2012) e Vieira (2009).Os principais resultados indicam que o sistema de controle interno do município estudado está bastante alinhado com o perfil de outras prefeituras evidenciados pelos trabalhos desenvolvidos anteriormente. Os principais resultados sugerem que o controle interno atua em diversas áreas, auxilia no planejamento e desenvolvimento da gestão pública municipal, entretanto, há pontos a serem melhorados. Sugere-se a contratação de servidores de carreira, bem como treinamentos periódicos e pontuais.

Palavras-chave: Administração. Controle interno. Gestão Pública Municipal.

\section{INTERNAL CONTROL SYSTEM IN THE PUBLIC MANAGEMENT OF A SMALL MUNICIPALITY}

\begin{abstract}
The objective of this work is to analyze internal control in the public management of a small municipality from three perspectives: (i) controller profile, (ii) internal control situation, and (iii) planning and execution of activities, and verify, if all of these are adherents to the legal regiment and are close to the reality of other municipalities already studied. The potential problem of internal control in the public management of small municipalities, highlighted by Castro (2013), is that in these prefectures, there is a tendency to centralize tasks in the same person, which is corroborated by previous work. However, few of these studies analyze the dynamics of internal control in small municipalities. In methodological terms, the research had a qualitative nature, a descriptive. In the data collection, in turn, a questionnaire was used,
\end{abstract}


with 19 questions, elaborated from the work of Roza, Lunkes and Alberton (2012) and Vieira (2009), and applied to the internal control officer of the city council in evidence. The main results of this research indicate that the internal control system of the studied municipality is very much in line with the profile of other prefectures evidenced by the work developed previously. The main results suggest that internal control operates in several areas, it aids in the planning and development of municipal public management, however, to the points to be improved, it is suggested the hiring of career servers, as well as periodic and punctual training.

\section{Keywords: Administration. Internal control. Municipal Public Management.}

\section{Introdução}

A administração pública nos últimos anos tem sido cenário de constantes fraudes, esquemas de corrupção, instabilidade política e econômica (RAMOS, 2010). Frente a esses desafios cresce a necessidade do Estado possuir ferramentas para controlar e fiscalizar os recursos públicos a fim de minimizar o máximo possível o impacto causado por estas situações. Neste contexto, o controle interno é introduzido como uma das ferramentas transversais para contribuir com o controle e a fiscalização do Estado. No setor público a existência de ferramentas de controle interno foi impulsionada a partir da Constituição Federal de 1988, e ainda reforçada pela Lei Complementar $n^{\circ} 101$ de 4 de maio de 2000, denominada Lei de Responsabilidade Fiscal - LRF, na qual foram inseridos mais controles internos na administração pública.

O controle interno é um conceito multidimensional amplamente discutido na literatura de controle de gestão (BOWRIN, 2004; AGBEJULE e JOKIPII, 2009). De acordo com Haron et al. (2010) o controle interno não é apenas um procedimento ou política executada, mas sim, um sistema continuamente operacional e integrado em todos os níveis de uma organização. Portanto, Bowrin (2004) sugere que o sistema de controle interno é um componente fundamental da estrutura de governança das organizações, e destina-se principalmente a direcionar e controlar as atividades da organização promovendo, transparência, responsabilidade, e justiça para todas as partes interessadas. Liu (2011) enfatiza que a falta de um sistema de controle interno pode prejudicar a organização de muitas maneiras, por isso uma maior dependência do sistema de controle está constantemente associada à alta expectativa de aumento da responsabilidade na organização.

De acordo com Silva (2009) o objeto do controle interno na administração pública é a própria gestão da instituição ou da entidade que representa, ou seja, todas as atividades, métodos e procedimentos adotados pela gestão, a qual é operacionalizada por meio de recursos humanos, materiais e financeiros. Na percepção de Silva (2002) os benefícios advindos de um sistema de controle interno serão inumeráveis, já que este torna possível um melhor emprego dos recursos públicos, bem com a identificação de medidas corretivas, a redução de fraudes, desperdícios e abusos por parte do gestor público. Bianchi (2010) argumenta que o papel do controle interno nas organizações do setor público é estabelecer parâmetros e ao mesmo tempo promover a responsabilidade de tomador de decisões.

Diversos trabalhos procuraram analisar o sistema de controle interno na gestão pública municipal se concentrando principalmente nos aspectos que perpassam seu perfil, sua organização e suas funcionalidades. Uma parte dessa literatura analisou os municípios de grande porte, regiões metropolitanas, ou conjuntos aleatórios de municípios (CAVALCANTE, PETER e MACHADO, 2011; ROZA, LUNKES e ALBERTON, 2012; VASCONCELOS et al. 2012). Recentemente outros trabalhos deram atenção especial a municípios específicos, analisando-os de forma mais profunda (HENRIQUE et al. 2016, ALVES e JÚNIOR, 2016). 
A partir dos trabalhos já desenvolvidos, e levando em consideração que no Brasil aproximadamente $70 \%$ dos municípios são considerados como de pequeno porte, ou seja, com população inferior a 20 mil habitantes (BERNARDO, SEDIYAMA e REIS, 2015), este trabalho procura o sistema de controle interno em um destes municípios. Castos (2013) sugere que estes municípios podem apresentar dificuldades em sistematizar o controle interno, pois existe a tendência de várias tarefas serem executadas por uma mesma pessoa o que ocasiona fortemente a centralização da gestão pública. Com esta concentração de atividades em uma mesma unidade ou pessoas, pode se perder a noção de segregação, já que o serviço nem sempre está nas mãos de servidores estáveis.

Dentro deste contexto, este trabalho possui como objetivo analisar o controle interno na prefeitura de um município de pequeno porte do Rio Grande do Sul, levando em consideração o perfil do controller, a situação do controle interno e o planejamento e execução das atividades. Nos municípios de pequeno porte, em que a dificuldade de oferecer os serviços sociais básicos e de manter padrões adequados de gestão pública, um sistema de controle interno eficiente e organizado pode ser um importante diferencial.

Este trabalho contribui para a literatura sobre controle de gestão na medida em que incorpora e apresenta as características de um município de pequeno porte, o que ainda é pouco explorado. Por essa razão, evidencia importantes implicações para o entendimento e avaliação da organização e das funcionalidades do controle interno.

\section{Referencial teórico}

\subsection{Controle interno na administração pública}

O Estado democrático alicerçado em um regime de representatividade atribui às pessoas eleitas pelo povo o poder da decisão política para decidir os rumos da sociedade. Contudo a complexidade e a pluralidade envolvidas no setor público, aliada a um regime jurídico que estabelece princípios e normas para o funcionamento do Estado, torna necessária a existência de mecanismos de controle com o intuito de que essa pessoa possa cumprir sua finalidade, sem denegrir os princípios da administração pública (GARCIA, 2011; MARX, 2015).

O controle interno, assim como as mais diversas formas de controle foram impulsionadas com a Lei de Responsabilidade Fiscal - LRF, entretanto no âmbito federal o controle interno já é um instrumento amplamente utilizado. A Lei $n^{\circ}$. 4.320, de 17 de março de 1964, foi um marco histórico para o controle interno na administração pública federal, pois foi responsável por apresentar e direcionar as competências do controle interno ao Poder Executivo e o controle externo ao Poder Legislativo. Para Castro (2013) o controle interno no âmbito federal ainda teve como marco a Medida Provisória n 480, de 27 de abril de 1994, a criação da Secretaria Federal de Controle Interno (SFC), e também a aprovação da Lei do Ciclo de Gestão (LEI $n^{\circ} 10.180$, de 6 de FEVEREIRO de 2001).

A partir de 2000 com o advento da LRF as obrigações dos agentes municipais foram aumentadas, já que essa lei proibiu que a gestão de um prefeito sobrecarregasse uma gestão futura. Para cumprir tais deveres o gestor público municipal precisa de controles internos eficientes que auxiliem na definição de estratégias, orçamentos, e outras atividades (SUZART, MARCELINO e ROCHA, 2011; ROZA, LUNKES e ALBERTON, 2012; CASTRO, 2013). Desta forma, segundo Castro (2013, p. 360) "o objetivo do controle interno é funcionar, simultaneamente, como um mecanismo de auxílio para o administrador público e como instrumento de proteção e defesa do cidadão". Ainda para o autor, um controle interno eficiente garante que os objetivos da organização pública sejam alcançados com maior facilidade, evitando assim, o desperdício, o abuso, os erros, as fraudes e as irregularidades (CASTRO, 2013). 
Contudo a administração pública, em razão da sua própria natureza apresenta dificuldades para o funcionamento qualificado de um sistema de controle interno. Na percepção de Silva (2002) o setor público é inclinado a certas peculiaridades, e por isso seu sucesso dependerá da modificação das rotinas e do comportamento das pessoas que executaram os controles, bem como no comportamento dos controlados. $\mathrm{O}$ autor sugere algumas características do setor público que dificultam o controle interno, destacando principalmente: (i) a dificuldade para medir resultados, pela falta de parâmetros externos; (ii) não há riscos de descontinuidade, porque a organização pública é essencial e não está sujeita a falências; (iii) relativa estabilidade funcional dos agentes; (iv) grande rotatividade das funções da alta administração (agentes políticos) devido à vinculação político-partidária, que pode mudar a cada quatro anos; e (v) não há risco financeiro ou patrimonial para os administradores, porque o investimento vem do povo.

Dentro desta situação problemática, Castro (2013) destaca que os Municípios devem organizar seus controles internos obedecendo a conceitos e legislações, e quando não houver condições administrativas ou financeiras de organizar uma área própria para a Auditoria Interna ou Secretaria de Controle Interno, deve ser criado, pelo menos um cargo de Assessor de Controle Interno, a ser ocupado por profissional qualificado, para executar o sistema de controle interno. O município, segundo as atribuições do art. 74 da Constituição Federal, deve manter sistemas de controle interno mediante lei de iniciativa do Poder Executivo, que normatizará sua atuação para o atendimento do art. 31 da Constituição Federal. Esta ainda deve tratar de normas gerais para sua implantação, já sua regulamentação que irá definir as rotinas e procedimentos, deve se dar por meio de decreto, que visa desenvolver suas atribuições dentro da própria estrutura do órgão que controla. Para isso se deve considerar a conjuntura dos órgãos e entidades da administração pública (SILVA, 2009).

Para Soares (2012) no âmbito municipal o sistema de controle interno é um instrumento importante para suporte e assessoria, que proporciona informações sinalizando ao gestor público a ocorrência de equívocos, desse modo é possível que sejam adotadas medidas para que tais apontamentos sejam corrigidos evitando prejuízos. Contudo para que o sistema de controle interno atue com propriedade é necessário que a administração municipal mantenha profissionais qualificados em número e qualidade no exercício das atividades.

A necessidade de organizar o controle administrativo do Estado já era preconizada pela Constituição Federal de 1946, o qual incumbiu o Tribunal de Contas da União - TCU o controle dos atos de gestão do Poder Executivo (Artigo 77 da Constituição Federal de 1946). Posteriormente, foi aprovada a Lei n. ${ }^{\circ}$ 4.320/64, que em seu artigo 76 foi responsável por introduzir os termos controle interno e controle externo, bem como a descrição de suas competências de exercício, sendo o primeiro conferido ao Poder Executivo e o segundo atribuído ao Poder Legislativo. De acordo com esta lei, cabe ao Poder Executivo exercer os três tipos de controle da execução orçamentária:

\footnotetext{
I - A legalidade dos atos de que resultem a arrecadação da receita ou a realização da despesa, o nascimento ou a extinção de direitos e obrigações;

II - A fidelidade funcional dos agentes da administração, responsáveis por bens e valores públicos;

III - o cumprimento do programa de trabalho expresso em termos monetários e em termos de realização de obras e prestação de serviços.
}

Além disso, a Lei 4.320/64 legitimou os princípios de planejamento, orçamento e controle, bem como instituiu o Orçamento Plurianual de Investimentos, o Orçamento por Programas e estabeleceu como objetivo primordial das novas técnicas orçamentárias a eficácia dos gastos públicos. Posteriormente com a promulgação da Constituição Federal de 1988 o controle interno que antes já era importante, agora se tornou indispensável em contexto 
municipal, como é mencionado no art. 31 "a fiscalização do Município será exercida pelo Poder Legislativo Municipal, mediante controle externo, e pelos sistemas de controle interno do Poder Executivo Municipal, na forma da lei". Ainda nos artigos 165, 166 e 167, está descrito o orçamento público por meio de três instrumentos que são: o Plano Plurianual (PPA), Lei Diretrizes orcamentárias (LDO) e a Lei Orçamentaria Anual (LOA).

O Plano Plurianual é um plano de médio prazo, que procura ordenar as ações do governo que levam ao atingimento dos objetivos e metas fixados para um período de quatro anos. Já a Lei de Diretrizes Orçamentárias compreende as metas e prioridades da Administração Pública, bem como as despesas de capital para o exercício financeiro subsequente; além disso, orienta a elaboração da Lei Orçamentária Anual, que estabelece as despesas e as receitas que serão realizadas no próximo ano (CASTELO, JÚNIOR e CASTELO, 2011).

A Lei Complementar $\mathrm{n}^{\circ} 101$, de 04 de maio de 2000, denominada Lei de Responsabilidade Fiscal - LRF é uma Lei Complementar de âmbito nacional, aplicável a todas as esferas e tem como objetivo, de acordo com Pereira e Arruda (2010, p. 2)"buscar o controle sobre os gastos que venham a ser absurdos e para tentar criar uma sociedade mais justa, com um razoável grau de igualdade social". Com o intuito de estabelecer normas de finanças públicas voltadas para a responsabilidade na gestão fiscal, a Lei de Responsabilidade Fiscal (LRF) tem suas diretrizes estabelecidas em seu art. $1^{\circ}, \S 1^{\circ}$, no qual consta que ,

\begin{abstract}
a responsabilidade na gestão fiscal pressupõe a ação planejada e transparente, em que se previnem riscos e corrigem desvios capazes de afetar o equilíbrio das contas públicas, mediante o cumprimento de metas de resultados entre receitas e despesas e a obediência a limites e condições no que tange à renúncia de receita, geração de despesas com pessoal, de seguridade social e outras, dívidas consolidada e mobiliária, operações de crédito, inclusive por antecipação de receita, concessão de garantia e inscrição em restos a pagar.
\end{abstract}

A Lei de Responsabilidade Fiscal dá ênfase ao fortalecimento e importância do controle interno, uma vez que nos artigos 52 e 53 exige a publicação de relatórios resumidos da execução orçamentária, e nos artigos 54 e 55 relatórios de gestão fiscal. Além disso, o artigo 59, determina que o Poder Legislativo, diretamente ou com o auxílio dos Tribunais de Contas, o sistema de controle interno de cada Poder e do Ministério Público, fiscalizarão o cumprimento das normas desta Lei Complementar, com ênfase no que se refere a:

\footnotetext{
I - atingimento das metas estabelecidas na lei de diretrizes orçamentárias;

II - limites e condições para realização de operações de crédito e inscrição em Restos a Pagar; III - medidas adotadas para o retorno da despesa total com pessoal ao respectivo limite, nos termos dos arts. 22 e 23 ;

IV - providências tomadas, conforme o disposto no art. 31, para recondução dos montantes das dívidas consolidada e mobiliária aos respectivos limites;

$\mathrm{V}$ - destinação de recursos obtidos com a alienação de ativos, tendo em vista as restrições constitucionais e as desta Lei Complementar;

VI - cumprimento do limite de gastos totais dos legislativos municipais, quando houver.
}

Portanto, o objetivo primordial da LRF é fortalecer a administração pública, buscando uma gestão responsável e transparente no trato dos recursos governamentais, por meio dos seus instrumentos de planejamento (PPA, LDO e LOA) e de controle da gestão físcal. As exigências da LRF, sinalizam a importância e a necessidade de informações precisas e confiáveis que possam garantir padrões adequados de gestão para o cumprimento dos limites estabelecidos pela lei.

\title{
2.2 Trabalhos anteriores
}


O presente tópico identifica estudos anteriores que discorram acerca do sistema de controle interno na administração pública. No que segue, é efetuada uma análise dos trabalhos encontrados, que se encontravam alinhados com o tema deste trabalho. O tema ainda é recente, por exemplo, Cavalcante, Peter, Machado (2008) analisaram as características dos órgãos de controle interno dos municípios da Região Metropolitana de Fortaleza no Estado do Ceará, buscando delinear o perfil desses órgãos. Para o desenvolvimento do trabalho, foi realizada uma pesquisa de campo com aplicação de questionários nos municípios que foram escolhidos de forma intencional. Dentre os aspectos relevantes, constatou-se que as unidades de controle interno dos municípios integrantes da amostra estudada não possuem autonomia, uma vez que, na maioria dos casos, são unidades integrantes de alguma secretaria ou órgão, o que reduz de significativamente a atuação do controle.

Vieira (2009) analisou como funcionam os controles internos nas Prefeituras do Estado do Rio de Janeiro e quais os benefícios inerentes a um bom sistema de controle interno nos órgãos públicos. Em termos metodológicos, trata-se de um estudo descritivo, no qual utilizouse um questionário constituído de cinco partes para a coleta de dados, sendo a primeira parte relativa à existência de Controladoria, a segunda a identificação e qualificação do Controlador, a terceira sobre a situação da Controladoria quanto à sua criação e forma de funcionamento básico, a quarta trata quanto à forma de planejamento e execução das atividades inerentes à Controladoria. Após a coleta de dados, foi verificado que a implementação das controladorias não foi uniforme em todas as Prefeituras, assim como sua criação, que aconteceu da forma tecnicamente melhor indicada, isto é, vinculadas diretamente ao prefeito; são comandadas por contadores; acompanham as diligências dos Tribunais de Contas; e procuram utilizar técnicas e práticas modernas, para a proteção do bem público. Quanto aos seus benefícios, constatou-se que os controles internos funcionam como um órgão indispensável de assessoria do gestor, na sua tomada de decisão, e por meio da ampla gama de vantagens contribuem para a defesa primaz do patrimônio público.

Soares (2012) por sua vez, analisou o sistema de controle interno da administração pública do município de Ouro Preto - MG. Em termos metodológicos, o trabalho se amparou no método do estudo de caso com abordagem qualitativa. Para coleta de dados foram realizadas entrevistas com os responsáveis pelo planejamento e/ou controle dos diferentes órgãos que integram a estrutura administrativa municipal, e por meio da técnica de análise de conteúdo buscou-se confrontar os olhares sobre as práticas do referido sistema. A partir das observações e análises realizadas, verificou-se que o controle interno auxilia no processo de fiscalização da gestão pública municipal, ou seja, constitui-se um instrumento de apoio aos gestores para a qualificação dos serviços prestados, contribuindo assim para a eficiência da gestão pública.

Vasconcelos et al. (2012) verificaram como vem sendo desenvolvido o controle interno nas prefeituras da região metropolitana de Natal no Rio Grande do Norte. Para tal, desenvolveram uma pesquisa bibliográfica e de campo, que por meio da aplicação de questionários e entrevistas em uma amostra não probabilista intencional analisaram o controle interno a luz da teoria e da legislação pertinente. Após a análise das entrevistas e questionários com os responsáveis pelo controle interno das prefeituras, constatou-se que das metas estabelecidas pelas prefeituras, aproximadamente $37 \%$ das metas foram cumpridas com auxílio do controle interno. Além disso, foi inferido que a gestão pública ainda não desmitificou o conceito de que os controles internos são implantados apenas para cumprir exigências legais.

Roza, Lunkes e Alberton (2012) analisaram o perfil dos controles internos de prefeituras, localizadas nas maiores cidades do estado do Rio Grande do Sul - RS. A pesquisa caracteriza-se como um levantamento, de caráter descritivo e abordagem qualitativa e quantitativa. $\mathrm{O}$ procedimento para coleta de dados consistiu na aplicação de um questionário com perguntas abertas e fechadas, dirigidas às controladorias ou controles internos, das 18 maiores cidades do Estado. Os resultados apontaram que 14 cidades possuem controle internos 
constituídos e que a formação de seus controllers, é em grande parte, de profissionais de nível superior, destacando-se dentre esses, os contadores (42\%). Quanto à estrutura hierárquica, foi constado que o controles internos em sua maioria (71\%) estão subordinados ao prefeito. E quanto as suas principais ações são de avaliação e controle das metas orçamentárias e financeiras (Plano Plurianual, Lei de Diretrizes Orçamentárias e Orçamento Anual), observadas as determinações da Lei de Responsabilidade Fiscal - LRF.

Alves e Moraes Júnior (2016) analisaram o sistema de controle interno na administração pública de Patos - PB. Em termos metodológicos, a pesquisa teve natureza qualitativa, de viés descritivo e procedimentos técnicos bibliográficos. Para coleta de dados, foi utilizado um questionário, com 17 questões, aplicados aos servidores que compõem a Secretaria de Controle Interno da Prefeitura. Os principais resultados indicam que os servidores do controle interno conhecem a realidade que vivenciam, e entendem que o controle interno municipal possui uma boa formação e executa suas atividades em diversas áreas; contribuindo assim para o desenvolvimento da gestão pública municipal. Entretanto, ainda houve o consenso de que necessita de mais servidores e espeço físico.

Henrique et al. (2016) verificaram quais são os mecanismos de controle interno adotados na prefeitura de Três Rios - RJ, e se estes estão aderentes ao regimento legal. Além disso, foi analisado o perfil dos responsáveis pelo controle interno e externo e se eles compreendem a sistemática em que estão envolvidos. Em termos metodológicos, utilizou-se da entrevista para levantar informações sobre os mecanismos de controle interno adotados pela prefeitura e da aplicação de questionários para avaliar o controle externo exercido pela Câmara. Os principais resultados sugerem que os mecanismos de controle adotados são importantes para o desenvolvimento das atividades administrativas no município, e que a prefeitura e a Câmara de Três Rios desempenham de forma satisfatória suas atribuições. Entretanto, o treinamento e contratação de pessoal, bem como a criação de departamentos específicos para auditoria e controle, foram aspectos sujeitos a melhorias.

\section{Características do município estudado}

O município estudado localiza-se na região noroeste do Estado do Rio Grande do Sul, possui uma população estimada para 2015 de 4.982 mil habitantes, área territorial de 130.434 $\mathrm{km}^{2}$ com uma densidade demográfica de $37,24 \mathrm{hab} / \mathrm{km}^{2}$. A economia do município bem como da região é oriunda principalmente da agricultura familiar, e da produção de grãos (IBGE, 2010). Segundo dados do Tribunal de Contas do Estado do Rio Grande do Sul, a receita do município em 2015 foi arrecadada por meio de: transferências correntes $(88,61 \%)$, transferências de capitais $(3,06 \%)$, receita tributária $(4,21 \%)$, receita de contribuição $(1,75 \%)$, receita patrimonial $(0,73 \%)$ e receita de serviços $(0,27 \%)$. O município previa para 2015 a arrecadação de R\$13.950.000,00, contudo arrecadou R\$13.391.615,12 tendo maior ápice de arrecadação no mês de dezembro (TCE/RS, 2015).

O Índice FIRJAN de Gestão Fiscal (IFGF), uma ferramenta de controle social que permite observar como os tributos pagos pela sociedade são administrados pelas prefeituras a partir dos indicadores de receita própria, gastos com pessoal, investimentos, liquidez e custo da dívida, indica que o município estudado apresentou em 2015 (ano base 2013) um IFGF de 0.4659, que o coloca no ranking estadual ocupando à $383^{\circ}$ colocação dos 497 municípios do Rio Grande do Sul. Dentre a totalidade de municípios do RS apenas 0,4\% dos municípios apresentam conceito A (superior a 0,8 pontos), $31,6 \%$ conceito B (entre 06 , e 0,8 pontos), $56,3 \%$ conceito $\mathrm{C}$ (entre 0,4 e 0,6 pontos) e $11,6 \%$ com conceito $\mathrm{D}$ (inferior a 0,4 pontos), este índice qualidade atribui ao município estudado um conceito $C$ desde o ano de 2006 , o que reforça ainda mais o necessidade de conhecer a organização e as funcionalidades dos sistemas e setores 
que atuam na gestão pública, uma vez que a atuação destes implica diretamente nos indicadores que compõe o cálculo do IFGF.

\section{Aspectos metodológicos}

Esta pesquisa caracteriza-se como uma investigação de abordagem qualitativa e de natureza descritiva. Para coleta de dados, foi utilizado um questionário, semiestruturado que se amparou nos trabalhos de Roza, Lunkes e Alberton (2012) e no de Vieira (2009), no qual a primeira parte é relativa ao perfil e qualificação do controller, a segunda relativa a existência do controle interno, no que diz respeito à sua criação e forma de funcionamento básico, e a terceira trata da forma de planejamento e execução das atividades inerentes ao controle interno. Gil (2008) salienta que para descrição de características de determinadas populações ou fenômenos, normalmente se utiliza técnicas padronizadas de coleta de dados, tais como o questionário e a observação sistemática.

A coleta de dados ocorreu no mês de novembro de 2016, a partir de uma visita à Prefeitura, que foi escolhida de forma intencional. Outros trabalhos que analisaram a organização ou as funcionalidades do sistema de controle interno na administração pública também definiram suas amostras de forma intencional. Beuren (2006) já descrevia amostras intencionais como uma importante estratégia na pesquisa em contabilidade. Por meio da figura 1 é possível observar as categorias e parâmetros utilizados para analisar o sistema de controle interno.

Figura 1 - Categorias de análise do controle interno

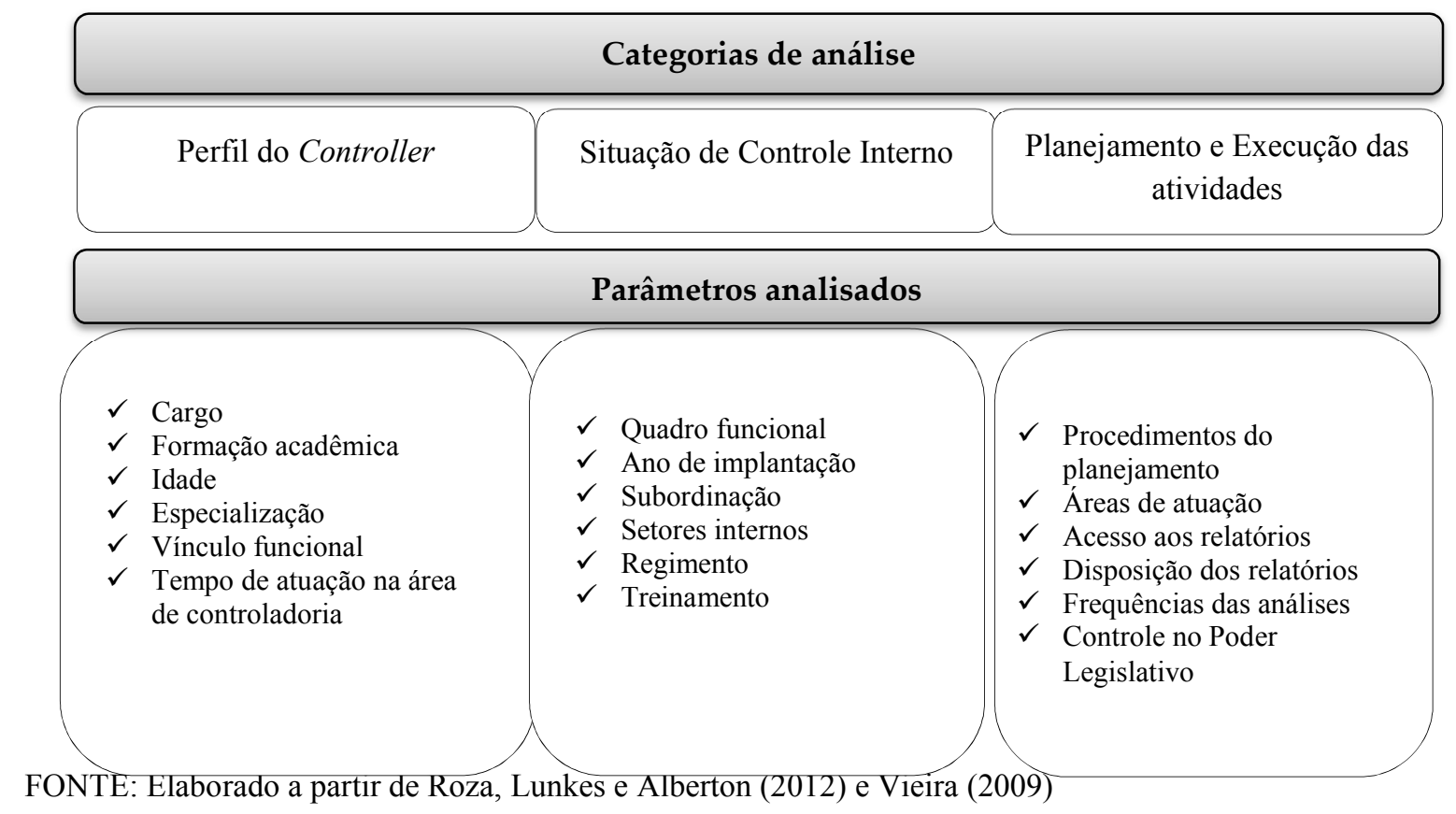

Os dados foram coletados por meio de entrevista semiestruturada com o controlador interno da Prefeitura. Os dados produzidos foram categorizados, confrontados com o problema de pesquisa, com o conteúdo explicitado nas seções anteriores e com evidências empíricas a fim de fundamentar as conclusões do estudo. Sendo a publicidade um dos princípios da administração pública, os dados que foram coletados para esta pesquisa devem 
estar disponíveis em diversas fontes, tais como o site da prefeitura e outras ferramentas do controle social.

\section{Resultados e discussões}

Inicialmente no Quadro 1, é apresento o perfil do controller que foi analisado a partir de cinco categorias de análise: cargo, formação acadêmica, idade, especialização, vínculo funcional e seu tempo de atuação na área de controle. O perfil do controller vem sendo amplamente analisado na literatura, principalmente no que diz respeito a suas características. Figuram nesse contexto aspectos que atentam a relevância de sua formação acadêmica e trajetória profissional, assim como suas tarefas básicas. Apesar dos diversos posicionamentos, existe a concordância de que deve principalmente acumular experiências das áreas contábil, financeira e administrativa. E que dentre as suas tarefas é salutar que ele informe a gestão sobre questões econômico-financeiras e suprir o gestor municipal com informações pertinentes à tomada de decisão (OLIVEIRA, 2004; FIGUEIREDO e GAGGIANO, 2004; LUNKES, 2013). Por meio do quadro a seguir é possível verificar as respostas das categorias.

Quadro 1 - Características do respondente

\begin{tabular}{|l|l|}
\hline \multicolumn{2}{|c|}{ PERFIL DO CONTROLER } \\
\hline Cargo & Controlador interno \\
\hline Formação acadêmica & Direito \\
\hline Idade & 32 \\
\hline Especialização & Gestão Pública Municipal \\
\hline Vínculo funcional com a prefeitura & Cargo comissionado \\
\hline Experiência profissional na área de controladoria & Menos de cinco anos \\
\hline
\end{tabular}

Fonte: Elaborado pelos autores (2018)

Os resultados indicam que este possui cargo comissionado, formação acadêmica em Direito, possui especialização em gestão pública municipal, e atua na área a menos de cinco anos. Evidências sugerem que os traços do perfil profissional não podem ser interpretados como determinantes para o desempenho do setor, uma vez que Padoveze (2004) alerta que o controller não é o responsável pelo alcance dos resultados planejados, cabe a controladoria o monitoramento dos resultados em relação aos números planejados, portanto é uma função de apoio e não da responsabilidade final. Além disso, Vasconcelos et al. (2012) em sua análise do controle interno nas prefeituras da região metropolitana de Natal - RN, não encontraram relação entre a formação acadêmica dos responsáveis pela controladoria nas prefeituras e melhores resultados de desempenho.

A situação do controle interno foi analisada por meio dos seguintes parâmetros: quadro funcional, ano de implantação, vinculação ou subordinação, existência de setores internos, regimento de sua estrutura, e treinamentos do quadro funcional. Demonstra-se no quadro 2, as sínteses dos resultados.

Quadro 2 - Situação do controle interno

\begin{tabular}{|l|l|}
\hline \multicolumn{2}{|c|}{ SITUAÇÃO DO CONTROLE INTERNO } \\
\hline Quadro funcional & Uma pessoa \\
\hline Anos de implantação & 2002 \\
\hline Vinculação/subordinação & Secretaria de Administração \\
\hline Existência de setores internos & Não possui \\
\hline Regimento & Lei Municipal \\
\hline Treinamento do quadro funcional & Aleatórios e esparsos \\
\hline
\end{tabular}

Fonte: Elaborado pelos autores (2018) 
Os aspectos que se referem à situação do controle interno na prefeitura estudada evidenciam que ela possui um quadro funcional de apenas uma pessoa, foi implantada no ano de 2002 por Lei Municipal, é vinculada hierarquicamente à Secretaria de Administração, possui treinamentos aleatórios e esparsos e não possui setores internos.

A literatura contábil já havia apresentado aspectos similares, Castos (2013) menciona que existe a tendência de várias tarefas serem executadas por uma mesma pessoa o que ocasiona fortemente a centralização da gestão pública. Os antecedentes empíricos também já haviam encontrado resultados similares, Henrique et al. (2016) ao analisar o controle interno no município de Três Rios - RJ, também observaram a falta de setores internos, o que é corroborado por Vieira (2009) em seus resultados quanto aos municípios de pequeno porte do Estado do Rio de Janeiro. Cavalcante, Peter e Machado (2011) em sua análise das características dos órgãos de controle interno dos municípios da região metropolitana de Fortaleza no Estado do Ceará, também identificaram que estes não possuem autonomia, uma vez que em sua maioria são unidades integrantes de outras secretarias. Alves e Júnior (2016) ao analisar o sistema de controle interno na administração pública municipal de Patos - PB, e Vieira (2009) também encontraram evidências que o treinamento dos servidores acontece esporadicamente.

O planejamento e a execução das atividades do controle interno foram analisados a partir dos seguintes parâmetros: elaboração do planejamento do controle interno, áreas de atuação, primeiro acesso aos relatórios, forma de dispor os relatórios, frequência das análises do controle interno, existência do controle interno no Poder Legislativo Municipal e relação com o Tribunal de Contas. Por meio do quadro 3, é possível observar as sínteses das respostas.

\begin{tabular}{|c|c|}
\hline \multicolumn{2}{|c|}{ PLANEJAMENTO E EXECUÇÃO DAS ATIVIDADES } \\
\hline $\begin{array}{l}\text { Elaboração do planejamento do controle } \\
\text { interno }\end{array}$ & $\begin{array}{l}\text { Proativo com, com planejamento prévio do que será feito e quando, } \\
\text { dentro de um plano de auditoria com cronograma de atividades } \\
\text { estabelecido }\end{array}$ \\
\hline Áreas de atuação do controle interno & $\begin{array}{l}\text { Tesouraria, controle de bens patrimoniais, almoxarifado, recursos } \\
\text { humanos, compras, contratações }\end{array}$ \\
\hline Primeiro acesso aos relatórios & Prefeito \\
\hline Forma de dispor os relatórios & São divididos por pontos analisados \\
\hline $\begin{array}{l}\text { Frequências das análises do controle } \\
\text { interno }\end{array}$ & Realizados durante todo o ano, com um cronograma estabelecido \\
\hline $\begin{array}{l}\text { Existência de controle interno no Poder } \\
\text { Legislativo Municipal }\end{array}$ & Não possui controle interno próprio \\
\hline Relação com o Tribunal de Contas & $\begin{array}{l}\text { O controle interno monitora as recomendações do Tribunal de } \\
\text { Contas }\end{array}$ \\
\hline
\end{tabular}

Fonte: Elaborado pelos autores (2018)

Quanto ao planejamento e execução das atividades, os dados levantados indicam que o planejamento é proativo e atua fortemente nas áreas de tesouraria, controle de bens patrimoniais, almoxarifado, recursos humanos, compras e contratações. $\mathrm{O}$ acesso aos relatórios é dado ao prefeito e os mesmos são divididos por ponto analisado. As análises são realizadas durante todo o ano e os relatórios são dispostos também de acordo com os pontos analisados. O Poder Legislativo Municipal não possui controle interno próprio e também não foi mencionado quem o faz. O controller menciona monitorar as recomendações do Tribunal de Contas do Estado do Rio Grande do Sul, bem como informa procurar o controle externo sempre que surgem situações imprevisíveis.

Vieira (2009) em sua análise das Prefeituras do Estado do Rio de Janeiro, encontrou nas de pequeno porte, resultados divergentes, nestas o órgão ou setor fiscalizado é quem primeiro tem acesso aos relatórios, tendo estes formatos pré-estabelecido. Além disso, identificou duas situações no que tange a frequência das análises realizadas pela Controladoria, em uma destas, 
as análises são realizadas somente em época específica, visando dar suporte à prestação de contas da Prefeitura, em outra, os exames são realizados durante todo o ano, com um cronograma pré-estabelecido, de forma que não há concentração relevante em determinado período do ano.

Outros resultados desta parte da análise também não se distanciam de achados anteriores. Alves e Júnior (2016) também encontram evidências da atuação do controle interno em diversas áreas, apensar de um quadro funcional limitado. As problemáticas envolvendo a subordinação das informações ao prefeito também são mencionadas por Cavalcante, Peter e Machado (2011) que ainda alertam que esta subordinação pode favorecer o prevalecimento de seus interesses.

\section{Considerações finais}

O presente estudo teve como objetivo analisar o sistema de controle interno em um município de pequeno porte no Rio Grande do Sul. A instituição de controles internos na administração pública constitui-se um grande diferencial, entretanto a natureza do setor público pode dificultar seu funcionamento. Para a eficiência da gestão pública novos valores precisam ser incorporados a fim de garantir a ética na aplicação de recursos públicos e no direcionamento destes. A Constituição Federal de 1988 aponta os controles internos como ferramentas para garantir além da cidadania um diferencial em todos os níveis funcionais em que se encontra.

Pode-se ressaltar que apesar das limitações, é verificado junto ao controle interno um conjunto importante de normas, rotinas e procedimentos, que por meio do planejamento proativo procura reduzir o erro, a fraude e minimizar a ineficiência da gestão pública. A Prefeitura estudada possui um sistema de controle interno constituído e procura executar as atividades pertinentes a esse controle dentro da Secretaria de Administração. Segundo as informações coletadas nesta pesquisa, os mecanismos, procedimentos e funcionalidades do sistema de controle interno adotados são importantes para a gestão pública municipal, e contribuem de forma proativa no planejamento e fiscalização.

Além disso, deve-se ressaltar as limitações do controle interno dentro da prefeitura estudada, destacando-se a falta de servidores de carreira, tendo em vista que o atual controlador interno, possui cargo comissionado. Além disso é necessária uma maior atenção ao treinamento dos servidores, já que quando bem preparados a ocorrência de irregularidades é reduzida o que pode implicar em uma melhor e mais eficiente aplicação dos recursos públicos.

Os principais resultados desta pesquisa indicam que o sistema de controle interno do município estudado está bastante alinhado com o perfil de outras prefeituras evidenciados pelos trabalhos desenvolvidos anteriormente. Apesar disso, os resultados desta pesquisa trazem importantes implicações para o entendimento da organização e das funcionalidades do controle interno, uma vez que a literatura aponta que municípios de pequeno porte estão mais inclinados a dificuldades se comparados com municípios de médio e grande porte.

Este trabalho teve como limitação a analise isolada de uma única prefeitura, entretanto este também pode ser um diferencial. Como verificado na construção da metodologia, outros trabalhos utilizaram amostras intencionas definidas por critérios como a acessibilidade, por exemplo. Estas amostras se concentram principalmente em municípios de grande porte e regiões metropolitanas, por isso estudos isolados em pequenos municípios são uma importante alternativa para a construção do conhecimento na área, já que estes exatamente pelos critérios de acessibilidade podem apresentar maior dificuldade na coleta de dados. Como sugestão de trabalhos futuros é recomendado ampliar um número de municípios, principalmente os de pequeno porte, bem como diversificar os métodos de pesquisa. 


\section{REAVI}

\section{Referências}

ALVES, A. G. S.; MORAES JÚNIOR, V. F. O Sistema de Controle Interno da Gestão Pública do Poder Executivo do Município de Patos/PB. Revista Evidenciação Contábil \& Finanças. v. 5, n. 2, p. 56-71, 2016.

AGBEJULE, A.; JOKIPII, A. Strategy, control activities, monitoring and effectiveness. Managerial Auditing Journal. v. 24, n. 6, p. 500-522, 2009.

BERNARDO, J. S.; SEDIYAMA, G. A. S.; REIS, A. O. Transparência e Accountability na Administração do Município de Viçosa - MG e seus Limítrofes. XII Congresso USP de Contabilidade e Controladoria. São Paulo, 2015. Anais do XII Congresso USP de Contabilidade e Controladoria, 2015.

BEUREN, I. M. Como elaborar trabalhos monográficos em contabilidade: teoria e prática. 3.ed. São Paulo: Atlas, 2006.

BIANCHI, C. Improving performance and fostering accountability in the public sector through system dynamics modelling: From an "external" to an "internal" perspective. Systems Research and Behavioral Science. v. 27, p. 361-384, 2010.

BOWRIN, A. R. Internal control in Trinidad and Tobago religious organizations. Accounting, Auditing \& Accountability Journal. v. 17, n. 1, p. 121-152, 2004.

BRASIL. Constituição da República Federativa do Brasil. São Paulo: Rideel, 1988.

1.1.1 BRASIL - LEI COMPLEMENTAR No. 101, DE 04 DE MAIO DE 2000. Estabelece normas de finanças públicas voltadas para a responsabilidade na gestão fiscal e dá 168 outras providências. Disponível em:

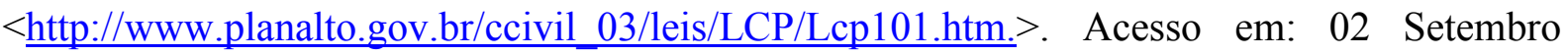
2017.

\section{1 .2}

1.1.3 BRASIL - LEI FEDERAL No. 4.320, DE 17 DE MARÇO DE 1964. Estatui normas gerais de Direito Financeiro para a elaboração e controle dos orçamentos e balanços da União, dos Estados, dos Municípios e do Distrito Federal. Disponível em: $<$ http://www.planalto.gov.br/ccivil 03/leis/L4320.htm.>. Acesso em: 15 Agosto 2017.

CASTELO, A. D. L.; JUNIOR, R. A. M. J.; CASTELO, S. L. Planejamento Governamental do Estado do Ceará e a Implantação da Rede Estadual de Planejamento. Revista Razão Contábil \& Finanças. v. 2, n. 1, p. 1-19, 2011.

CASTRO, D. P. de. Auditoria, contabilidade e controle interno no setor público. 5. ed. São Paulo: Atlas, 2013. 
CAVALCANTE, D. S.; PETER, M. G. A.; MACHADO, M. V. V. Organização dos órgãos de controle interno municipal no Estado do Ceará: um estudo na Região Metropolitana de Fortaleza. Advances in Scientific and Applied Accounting. v. 4, n .1, p. 24-43, 2011.

1.1.4 FIGUEIREDO, S.; CAGGIANO, P. C. Controladoria: teoria e prática. $3^{\text {a }}$ ed. São Paulo: Atlas, 2004.

GARCIA, L. M. Análise do controle interno do Poder Executivo Federal Brasileiro sob a perspectiva de Pierre Bourdieu: História Social como possibilidade de compreensão da produção e reprodução de práticas dos agentes. 2011. 240f. Tese (Doutorado em Administração) - Faculdade de Ciências Econômicas da Universidade Federal de Minas Gerais, 2011.

GIL, A. C. Como elaborar projetos de pesquisa. 4. ed. São Paulo: Atlas, 2008.

HARON, H.; IBRAHIM, D. D. N.; JEYARAMAN, K.; CHYE, O. H. Determinants of internal control characteristics influencing voluntary and mandatory disclosures: A Malaysian perspective. Managerial Auditing Journal. v. 25, n. 2, p. 140-159, 2010.

HENRIQUE, J. C.; CHAGAS, L.; GUIMARÃES, V. A.; LEAL JUNIOR, I. C. Análise da Sistemática de Controle Interno Do Município de Três Rios. Revista Pensamento Contemporâneo em Administração. v. 10, n. 3, p. 31-41, 2016.

IBGE - INSTITUTO BRASILEIRO DE GEOGRAFIA E ESTATÍSTICA. Cidades.

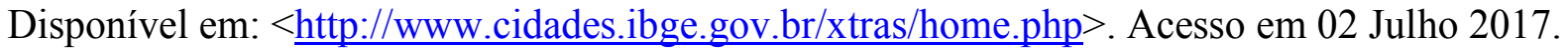

IFGF - ÍNDICE FIRJAN DE GESTÃO FISCAL. Disponível em: < http://www.firjan.com.br/ifgf/>. Acesso em 03 Julho 2017.

LIU, O. Outcomes assessment in higher education: Challenges and future research in the context of voluntary system of accountability. Educational Measurement: Issues and Practice. v. 30, p. 2-9, 2011.

LUNKES, R. Controladoria: funções e desenvolvimento. Revista Gesto. v. 1, p. 104-115, 2013.

MARX, C. A. A CGU e a dualidade do papel do controle interno no Brasil. 2015. 95f. Dissertação (Mestrado em Gestão e Políticas Públicas) - Escola de Administração Pública e de Empresas da Fundação Getúlio Vargas, 2015.

NUNES, G. S. F.; SANTOS, V.; FARIAS, S.; SOARES, S. V.; LUNKES, R. Análise dos Instrumentos de Transparência contidos na Lei de Responsabilidade Fiscal nos municípios da Região Sul. Revista Ambiente Contábil. v. 5, p. 128-150, 2013.

OLIVEIRA, L. M. de. Controladoria estratégica. 2. ed. - São Paulo: Atlas, 2004.

OLIVEIRA, G. C. A importância do controle interno nas finanças públicas. 2013. 47f. Dissertação (Mestrado em Economia) - Faculdade de Economia, Administração e Contabilidade da Universidade de Brasília, 2013. 
PADOVEZE, C. L. Controladoria Estratégica e Operacional: conceitos, estrutura, aplicação. 2 ed. São Paulo: Cengage Learning, 2011.

RAMOS, P. R. A. Corrupção na Administração Pública e crimes de 'lavagem' ou ocultação de bens, direitos e valores. Revista Mineira de Contabilidade. v. 40, n. 40, p. 14-23, 2010.

ROZA, M. M. C. DA.; LUNKES, R. J.; ALBERTON, L. Perfil dos controles internos em prefeituras do Rio Grande do Sul: Uma análise nas maiores cidades gaúchas. Revista de Contabilidade do Mestrado em Ciências Contábeis da UERJ (online). v. 17, n. 1, p. 18-31, 2012.

SILVA, P. G. K. da. O papel do controle interno na administração pública. Contexto. v. 2, n. 2, p. 1-12, 2002.

SOARES, L. R. Características do sistema de controle interno municipal: um estudo da prefeitura municipal de Ouro Preto. 2012. 96f. Dissertação (Mestrado em Administração) Universidade FUMEC, 2012.

1.1.5 SUZART, J, A. S.; MARCELINO, C. V.; ROCHA, J. S. As instituições brasileiras de controladoria pública - teoria versus prática, Contabilidade, Gestão e Governança. v. 14, n. 1, p. 44-56, 2011.

1.1.6

TCE/RS - TRIBUNAL DE CONTAS DO ESTADO DO RIO GRANDE DO SUL. Controle

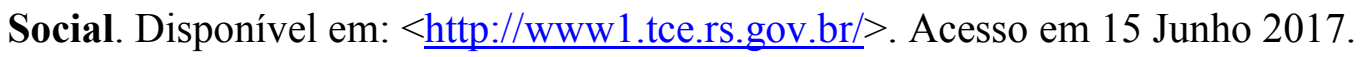

VASCONCElOS, M. T. C; SAMPAIO, F. J. C. S.; Silva NETO, A. F.; DUQUE, C. Funcionalidade do controle interno nos municípios: um estudo nas prefeituras de uma região metropolitana do nordeste brasileiro. Advances in Scientific and Applied Accounting, v. 5, n. 2, p. 201-221, 2012.

1.1.7 VIEIRA, R. A. A importância do controle interno numa visão moderna de gestão pública. 2009. 121f. Dissertação (Mestrado em Contabilidade) - Universidade do Estado do Rio de Janeiro, 2009. 